\title{
Quality of life on randomized treatment for isolated systolic hypertension: results from the Syst-Eur Trial
}

\author{
Astrid E. Fletcher ${ }^{\mathrm{a}}$, Christopher J. Bulpitt ${ }^{\mathrm{b}}$, Lutgarde Thijs ${ }^{\mathrm{c}}$, \\ Jaakko Tuomilehto ${ }^{d}$, Riitta Antikainen ${ }^{\mathrm{e}}$, Alfredo Bossini9, John Browne ${ }^{\mathrm{i}}$, \\ Joseph Duggan', Kalina Kawecka-Jaszcz', Paula Kivinen ${ }^{f}$, Cinzia Sarti ${ }^{d}$, \\ Laura Terzolih and Jan A. Staessen ${ }^{\mathrm{c}}$, on behalf of the Syst-Eur Trial \\ Investigators
}

Objective To compare quality of life in elderly patients with isolated systolic hypertension allocated randomly to groups to receive placebo or active treatment in the Systolic Hypertension in the Elderly Trial.

Design Double-blind randomized controlled trial.

Methods Patients aged 60 years were allocated randomly to groups to receive first-line treatment with nitrendipine (with second- and third-line enalapril and hydrochlorothiazide) or placebo. Trained interviewers administered trail-making tests (Trail A and B), Brief Assessment Index (a measure of depressed mood) and four subscales from the Sickness Impact Profile (Ambulation, Social Interaction, Sleep and Rest, and Home work).

Results Six hundred and ten patients completed a baseline and at least one follow-up questionnaire. Trailmaking scores were slower in actively treated patients, especially in the first 6 months of follow-up when the between-group effect sizes were 0.25 [95\% confidence interval $(\mathrm{Cl}) 0.07$ to 0.43 ] for Trail-making $A$ and 0.13 (95\% $\mathrm{Cl}-0.05$ to 0.31 ) for Trail-making B. Across the 4 years of follow-up, patients receiving active treatment were more likely to report problems on the Social Interaction scale than were placebo-treated patients (odds ratio 1.32, 95\% Cl 1.02 to 1.69 ), equivalent to a $7 \%$ difference. There were no significant differences between active and placebo treatment in the other Sickness Impact Profile dimensions or in the measure of depression.

\section{Introduction}

There is now substantial evidence from randomized controlled trials of the benefits of pharmacological treatment of isolated systolic hypertension in older people. A recent meta-analysis of eight trials found risk reductions of $13 \%$ for all-cause mortality, $30 \%$ for

Note: This work was presented by A. Fletcher et al. as an oral presentation at the XIth European Meeting on Hypertension Milan, Italy, 15-18 June, 2001.
Conclusions Active treatment in the Systolic Hypertension in Europe trial was associated with some small adverse impacts on quality of life. J Hypertens 20:2069-2079 @ 2002 Lippincott Williams \& Wilkins.

Journal of Hypertension 2002, 20:2069-2079

Keywords: quality of life, randomized trials, Trail-making, isolated systolic hypertension, pharmacological treatment

${ }^{a}$ Centre for Ageing and Public Health, London School of Hygiene \& Tropical Medicine, ${ }^{b}$ Care of the Elderly, Imperial College Faculty of Medicine, London, UK, cStudy Co-ordinating Centre, Hypertension and Cardiovascular Rehabilitation Unit, Department of Molecular and Cardiovascular Research, University of Leuven, Leuven, Belgium, d Department of Epidemiology and Health Promotion, National Public Health Institute, Helsinki, e Department of Internal Medicine, University of Oulu, Oulu and ${ }^{f}$ Department of Community Health and General Practice, University of Kuopio, Finland, ${ }^{9}$ Centro Ipertensione Arteriosa e Nefropatie, Università degli Studi di Roma 'La Sapienza', Rome and h Centro di Riabilitazione Cardiovascolare, Ospedale Seregna, Milan, Italy, 'Blood Pressure Unit, Beaumont Hospital, Dublin, Ireland and ${ }^{\mathrm{j} C}$ Cardiac Department, Jagielonnian University Medical College, Krakow, Poland. A full list of the collaborating investigators in the Syst-Eur quality of life study is given in the Appendix.

Sponsorship: The Syst-Eur Trial was a concerted action of the BIOMED Research Programme, sponsored by the European Union. The trial was sponsored by Bayer AG, Wuppertal Germany. Study medication was donated by Bayer AG and Merck Sharpe and Dohme Inc., West Point, PA, USA. Conflicts of interest: None.

Correspondence to Professor Astrid Fletcher, Centre for Ageing and Public Health, Department of Epidemiology and Population Health, London School of Hygiene and Tropical Medicine, Keppel St, London WC1E 7HT, UK. (Reprints will not be available.)

Tel: +44 207927 2253/4; fax: +44 207580 6897;

e-mail: Astrid.Fletcher@Lshtm.ac.uk

Received 14 March 2002 Revised 17 June 2002

Accepted 24 June 2002

strokes, and $23 \%$ for coronary events [1]. An important consideration in the treatment of patients with hypertension is that the drugs used to reduce the blood pressure should not be detrimental to the patient's everyday health-related quality of life. In long-term placebo-controlled treatment trials in older people, the effects on quality of life have been reported only for the Systolic Hypertension in the Elderly Program (SHEP) trial [2,3] and from the Medical Research 
Council (MRC) trial of systolic hypertension for the substudies measuring cognitive function [4]; the results for mood disorders are awaited. The Systolic Hypertension in Europe (Syst-Eur) trial, a placebo-controlled trial of the treatment of elderly patients with isolated systolic hypertension in Europe also included a side project to measure health-related quality of life. In this paper, we report the results of the quality of life assessment. We have previously presented the baseline measures of quality of life for 631 patients recruited by 1 October 1995 [5]. The trial was stopped in February 1997 at the second interim analysis when the monitoring boundary for stroke events was crossed in favour of active treatment.

\section{Methods}

\section{The Syst-Eur Trial}

The procedure for the Syst-Eur trial has been published in full elsewhere [6]. Eligible patients had to be at least 60 years old and with an average sitting blood pressure (mean of six measurements obtained at three visits 1 month apart in the run-in period) of 160 $219 \mathrm{mmHg}$ systolic and $>95 \mathrm{mmHg}$ diastolic, and an average standing systolic pressure of $140 \mathrm{mmHg}$ or more. After stratification by centre, sex and previous cardiovascular complications, eligible patients were randomly assigned to double-blind active or placebo treatment by means of a computerized random function at the coordinating office. Active treatment consisted of nitrendipine (10-40 $\mathrm{mg}$ daily) combined, if necessary, with enalapril (5-20 mg daily) and hydrochlorothiazide (12.5-25 $\mathrm{mg}$ daily). The patients in the control group received matching placebos. The active drugs were step-wise titrated to reach goal pressure, which was defined as a sitting systolic blood pressure less than $150 \mathrm{mmHg}$, with a reduction from baseline (at the time of allocation to groups) of at least $20 \mathrm{mmHg}$. Over an 8 year period, 4695 patients were recruited into the study. At the time the trial was stopped, the median follow-up was 2 years (range 1-97 months). The trial results showed that active treatment was associated with a $42 \%$ reduction in strokes $(P<0.003)$ and $26 \%$ reduction in cardiac events $(P<0.03)$ [7].

\section{Assessment of quality of life}

Thirty-three centres in 12 countries participated in the quality of life side project (see Appendix for full details of centres and locations). Patients were recruited from hypertension clinics or general practitioners from centres in Finland (51\%), Italy (12.5\%), UK and Ireland (10\%), Russia (5.5\%) and Spain (4\%), with smaller numbers from Poland, Belgium, Slovakia, Lithuania, Romania and Croatia. Full details of the procedure for quality of life assessment have been published elsewhere [8]. The questionnaire, which was administered by an interviewer, covered a variety of aspects of quality of life and included well-established and tested scales.

Section 1 of the questionnaire was two short tests, Trail-Making Test $A$ and Trail-Making Test B [9]. These are tests of coordination, visual scanning and visualmotor speed. In the Trail-making test A, patients were required to connect up the numbers 1 to 25 sequentially. Trail-making test B consists of an alternating sequence of numbers and letters that patients must connect up in the correct sequence. The time taken to record the sequence correctly for each test was recorded. Studies have shown that these tests are able to pick up deteriorations in performance related to hypertensive arterial changes $[10,11]$.

Section 2 consisted of the following dimensions of the Sickness Impact Profile (SIP) [12]:

Ambulation: describes the effect of poor health on the ability to walk and move around freely.

Social Interaction: describes the effects of poor health on relationships with family and friends, and enjoyment of social activities.

Home work: describes the effects of poor health on housework, and other primarily physical activities related to looking after the home.

Sleep and Rest: describes the effect of poor health on daytime and night-time rest.

Each section included a set of statements, which were individually read to the patient. They responded if they agreed with the statement, and also indicated if it was due to their health.

Section 3 was the Card Version of the Brief Assessment Index (BAI) to assess depression [13]. The patient was asked to respond to each of 19 statements on separate cards shown to them by the interviewer.

Section 4 consisted of a checklist of 32 symptoms covering the expected symptoms associated with hypertension and the side effects of the antihypertensive drugs to be used in the trial. The results of the symptom assessment are not included in this paper.

The quality of life questionnaires were translated from English into the local language of each centre. Standard procedures were followed, including forward and back translation and further modifications as necessary. All patients in each centre who entered into the run-in phase were invited to take part in the side project. The nature of the questionnaire was explained fully to patients and full confidentiality was assured. Interviewers attended a training session at the coordinating centre in the administration of the questionnaire and tests. In addition, the interviewers were required to 
administer the questionnaire under standard conditions (separate and quiet room, before the patient saw the doctor or had their blood pressure measured).

\section{Objectives and sample size calculations}

The main objectives of the side project were to compare active and placebo treatments on all five outcomes (i.e. the four SIP dimensions and the BAI), and the two tests of Trail-making. On the basis of results from a pilot study of 52 men and women older than 60 years at the Hammersmith Hospital, an $\alpha$ of 0.01 and power of $90 \%$, we estimated that about 330 individuals in each group were required to detect an approximately $10 \%$ difference in quality of life measures equivalent to a 0.2 effect size. This number was increased to 400 per group on the assumption of an $80 \%$ response rate to the side project.

\section{Statistical methods}

The SIP dimensions were scored as follows: each statement had a weighted score and the total dimension score was the sum of the weighted responses divided by the maximum available for that dimension, thus converting the scale to a $0-100$ score, with 0 representing good quality of life (i.e. no problems) and 100 representing poor quality of life (maximum number of affirmative statements). The weights used in the SystEur trial were derived from those used in a large study of disability in the UK [14]. The BAI was scored by summing all the positive responses; two statements ('I have given up hope' and 'I have seriously considered suicide') were given double scores. The range of scores in the BAI was 0 (i.e. no problems) to 21 (maximum problems). Patients' scores were also expressed as a percentage of maximum.

We undertook the following analyses:

(1) Analyses based on change from baseline to 6 months and from baseline to 2 years. The period of 2 years was chosen because it was the median follow-up time for all Syst-Eur patients in the main trial. Changes in SIP and BAI scores were tested using the Wilcoxon two-sample test for medians. Trail-making times were $\log$ transformed and analysed by $t$ tests. Changes from baseline were calculated by taking the antilog of the difference between the log-transformed baseline and follow-up Trail-making times and expressing the obtained ratio on a percentage scale. Between randomized groups, effect sizes were calculated as the mean differences of the treatment effects in the active and placebo groups divided by the pooled standard deviation and confidence ranges calculated as described by Hedges and Olkin [15].

(2) Analyses for all patients across the 4-year period of follow-up time for all patients with a baseline measure- ment and utilizing all available data for each patient. The follow-up period did not go beyond 4 years because very few patients [55 (19\%) receiving placebo and $56(17 \%)$ receiving active treatment] had completed questionnaires beyond this period. We used a multilevel modelling approach with generalized estimating equations [16] to estimate treatment and time effects taking account of age and baseline score, and also to check for possible interactions between treatment and time. For these analyses, the SIP and BAI scores were dichotomized as no problems $($ score $=0)$ or problems (score $>0$ ).

These analyses were conducted for the patient population defined by (a) intention-to treat (ITT) and (b) on randomized treatment (ORT) strategy. All analyses were performed using SAS 8.0 (SAS Institute, Cary, North Carolina, USA). The ITT population included all patients according to their randomization group, irrespective of whether they had been withdrawn from the double-blind part of the trial. The ORT analyses were based only on patients who continued with double-blind treatment.

\section{Results}

Figure 1 shows the flow chart for the study. The 33 centres participating in the quality of life side project included about $25 \%$ of all trial patients. However, because of the time taken to start the quality of life side project in the centres (ethics approval, translation of questionnaires and nurse training), about $33 \%$ of the potential patients had already been allocated to groups and therefore were not included. In each arm of the study, just over 100 patients who should have participated in the quality of life side project did not do so, but the reasons for not being included were largely unknown. Of the 344 patients in the placebo group and the 364 active-treatment patients who completed a baseline questionnaire, 289 and 321, respectively, also completed at least one follow-up questionnaire; 55 in the placebo group and 43 in the active-treatment group did not complete any follow-up questionnaires, the reason for non-completion being unknown in the majority of cases (most of these patients were still receiving double-blind treatment). The numbers in the ITT and ORT analyses were similar: for placebo, 289 in ITT and 276 in ORT, and for the actively treated group, 321 in ITT and 317 in ORT. In the ITT analysis, questionnaires were available for $47 \%$ of patients who received placebo and were followed for at least 4 years, and for similar proportions (46\%) in the active-treatment group. For the ORT analysis, $34 \%$ of those receiving placebo and $39 \%$ of those in the activetreatment group provided questionnaires for at least 4 years. In the early part of the trial, questionnaires were available at the second year of follow-up for $82 \%$ 
Fig. 1

Randomized in Syst-Eur main

trial

$n=4695$

Randomized in 33 centres

participating in quality of life

side project

$\mathrm{n}=1348$
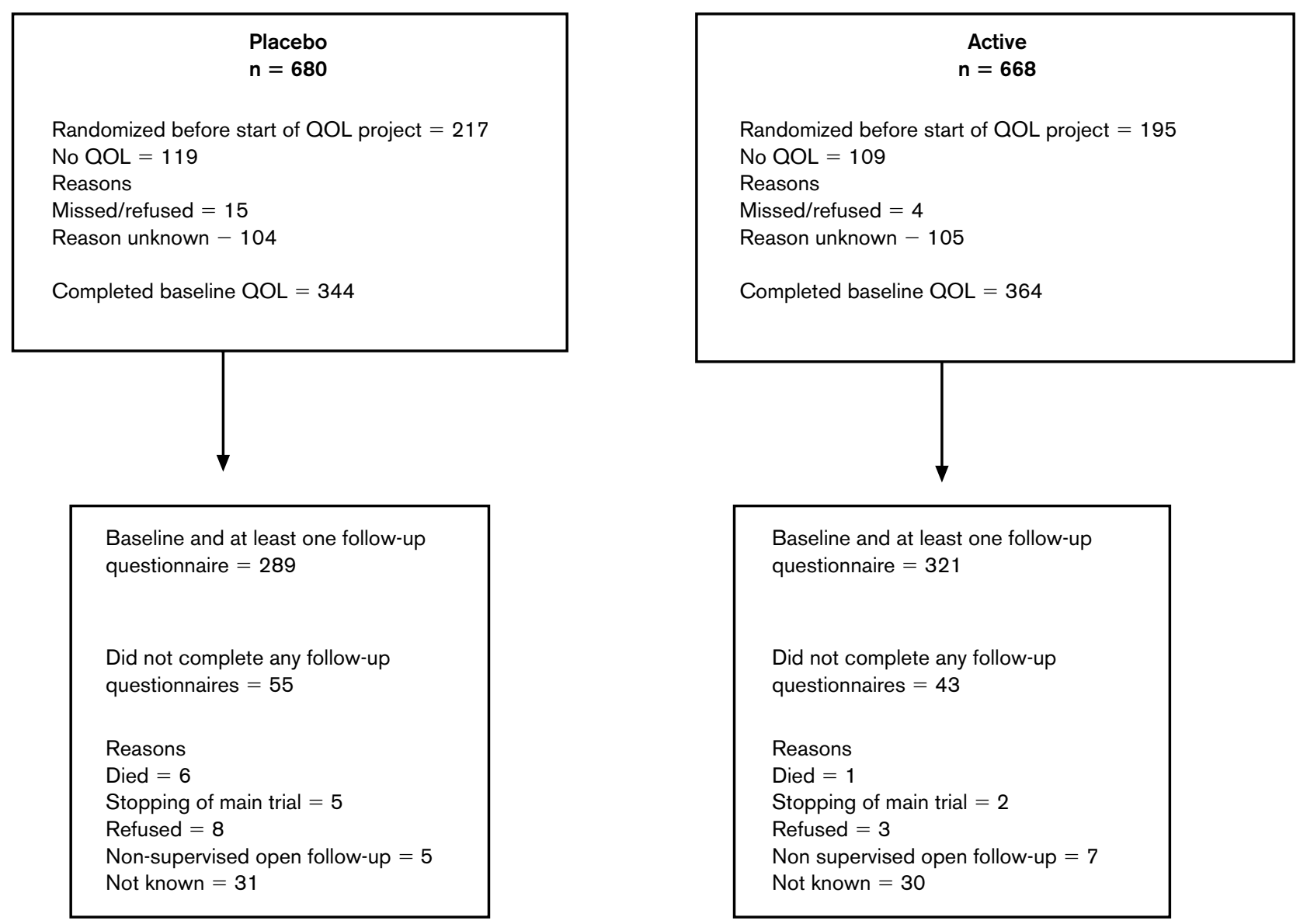

Study flow chart.

of both groups for the ITT analyses, and for $67 \%$ of placebo-group patients and $75 \%$ of active-treatment group patients for the ORT analyses, reflecting the earlier and greater rate of withdrawal from the placebo group.
Table 1 gives the characteristics and scores for Trailmaking tests and quality of life by randomized treatment at baseline for the 610 patients who completed at least one follow-up quality of life questionnaire. $\mathrm{Pa}$ tients in the active-treatment and placebo groups were 
Table 1 Characteristics of patients at baseline

\begin{tabular}{|c|c|c|}
\hline & $\begin{array}{l}\text { Placebo } \\
(n=289)\end{array}$ & $\begin{array}{l}\text { Active treatment } \\
\quad(n=321)\end{array}$ \\
\hline Age (years) & $70.2 \pm 6.0$ & $70.8 \pm 6.3$ \\
\hline Men & $91(31.5)$ & $96(29.9)$ \\
\hline Systolic blood pressure $(\mathrm{mmHg})$ & $172.2 \pm 9.9$ & $173.3 \pm 10.6$ \\
\hline Diastolic blood pressure $(\mathrm{mmHg})$ & $86.6 \pm 5.4$ & $85.6 \pm 5.7$ \\
\hline \multicolumn{3}{|l|}{ BMI $\left(\mathrm{kg} / \mathrm{m}^{2}\right)$} \\
\hline Men & $26.2 \pm 2.9$ & $26.4 \pm 3.5$ \\
\hline Women & $27.6 \pm 4.4$ & $26.9 \pm 3.9$ \\
\hline Cardiovascular complications & $94(32.5)$ & $102(31.8)$ \\
\hline History of stroke & $4(1.4)$ & $7(2.2)$ \\
\hline History of myocardial infarction & $7(2.4)$ & $9(2.8)$ \\
\hline Diabetes & $20(6.9)$ & $23(7.2)$ \\
\hline Current smokers & $24(8.3)$ & $28(8.7)$ \\
\hline Current drinkers & $98(34.0)$ & $109(34.0)$ \\
\hline$\geqslant 1$ unit alcohol/day & $34(11.8)$ & $42(13.1)$ \\
\hline Previous treatment & $97(33.6)$ & $105(32.7)$ \\
\hline ADL score 6 & 284 (98.3) & $320(99.7)$ \\
\hline Trail-making test $\mathrm{A}(\mathrm{s})$ & $81 \pm 64$ & $78 \pm 47$ \\
\hline Geometric mean & $58(n=281)$ & $59(n=317)$ \\
\hline Trail-making test B (s) & $190 \pm 121$ & $201 \pm 145$ \\
\hline Geometric mean & $154(n=273)$ & $153(n=303)$ \\
\hline \multicolumn{3}{|l|}{ Ambulation } \\
\hline Median (interquartile range) & $0(9.2)$ & $0(9.2)$ \\
\hline$\%>0$ & 43 & 40 \\
\hline \multicolumn{3}{|l|}{ Social interaction } \\
\hline Median (interquartile range) & $3.5(9.8)$ & $3.5(11.7)$ \\
\hline$\%>0$ & 55 & 54 \\
\hline \multicolumn{3}{|l|}{ Home work } \\
\hline Median (interquartile range) & $0(8.6)$ & $0(5.4)$ \\
\hline$\%>0$ & 38 & 41 \\
\hline \multicolumn{3}{|l|}{ Sleep and rest } \\
\hline Median (interquartile range) & $0(14.5)$ & $0(14.5)$ \\
\hline$\%>0$ & 33 & 27 \\
\hline \multicolumn{3}{|l|}{ Brief assessment index } \\
\hline Median (interquartile range) & $4.8(9.5)$ & $4.8(14.3)$ \\
\hline$\%>0$ & 56 & 59 \\
\hline
\end{tabular}

Values are mean $\pm S D$, number (\%), or number. BMl, body mass index; $A D L$, activities of daily living. similar for most demographic and clinical variables. In both groups, SIP scores were low, with median values of 0 for three of the four SIP dimensions, and a median of 3.5 on the social interaction dimension. The median BAI score was also low (4.8) compared with a recommended cut-off point of 15 for possible clinical depression. Thus, at entry to the trial, patients reported little disability and showed high levels of social interaction and mental well-being. The patients in the quality of life side project were also very similar to those in the main trial [7] in respect of all entry characteristics, with the exception of previous antihypertensive medication (in the quality of life project, $34 \%$ in the placebo group and $33 \%$ in the active treatment group had previously been treated, compared with 47 and $46 \%$, respectively, in the main trial). Those eligible for the quality of life project but who did not participate were also less healthy than participants ( $46 \%$ of non-participants had cardiovascular complications at entry, compared with $32 \%$ of participants, and $51 \%$ had been treated previously).

\section{Treatment effects \\ Quality of life (SIP and BAI)}

Table 2 presents the results for the ITT population for changes from baseline in SIP and BAI scores at the two time-points of 6 months and 2 years. No differences between active and placebo treatments were observed. The ORT analyses for these time-points were essentially similar. Figure 2 shows the proportions scoring $>0$ on each of the SIP and BAI scores over the 4 years

Table 2 Within-treatment changes in quality of life measures from baseline to 6 months and 2 years (intention-to-treat analysis)

\begin{tabular}{|c|c|c|c|c|c|c|}
\hline & \multicolumn{6}{|c|}{ Differences from baseline at: } \\
\hline & \multicolumn{3}{|c|}{6 months $\dagger$} & \multicolumn{3}{|c|}{2 years $\dagger$} \\
\hline & $\begin{array}{l}\text { Placebo } \\
(n=232)\end{array}$ & $\begin{array}{l}\text { Active treatment } \\
\quad(n=263)\end{array}$ & $P \dagger$ & $\begin{array}{l}\text { Placebo } \\
(n=236)\end{array}$ & $\begin{array}{l}\text { Active treatment } \\
\quad(n=264)\end{array}$ & $P$ \\
\hline \multicolumn{7}{|c|}{ Sickness impact profile } \\
\hline \multicolumn{7}{|l|}{ Ambulation } \\
\hline Median & 0 & 0 & & 0 & 0 & 0.44 \\
\hline 5th to 95th PI & -13 to 11 & -11 to 13 & 0.50 & -12 to 15 & -13 to 15 & \\
\hline \multicolumn{7}{|l|}{ Social interaction } \\
\hline Median & 0 & 0 & & 0 & 0 & 0.38 \\
\hline 5th to 95th $\mathrm{PI}$ & -13 to 14 & -13 to 7 & 0.48 & -17 to 14 & -19 to 9 & \\
\hline \multicolumn{7}{|l|}{ Home work } \\
\hline Median & 0 & 0 & & 0 & 0 & 0.46 \\
\hline 5th to 95th PI & -16 to 11 & -13 to 17 & 0.10 & -14 to 16 & -13 to 24 & \\
\hline \multicolumn{7}{|l|}{ Sleep and rest } \\
\hline Median & 0 & 0 & & 0 & 0 & 0.14 \\
\hline 5th to 95th PI & -23 to 19 & -14 to 14 & 0.69 & -25 to 14 & -16 to 14 & \\
\hline \multicolumn{7}{|c|}{ Brief assessment index } \\
\hline Median & 0 & 0 & & 0 & 0 & \\
\hline 5th to 95th PII & -14 to 10 & -14 to 10 & 0.97 & -14 to 14 & -19 to 14 & 0.41 \\
\hline
\end{tabular}

$\dagger$ A negative score denotes improvement; $₫ P$ value for difference in medians. $\mathrm{PI}$, percentile interval. 
Fig. 2
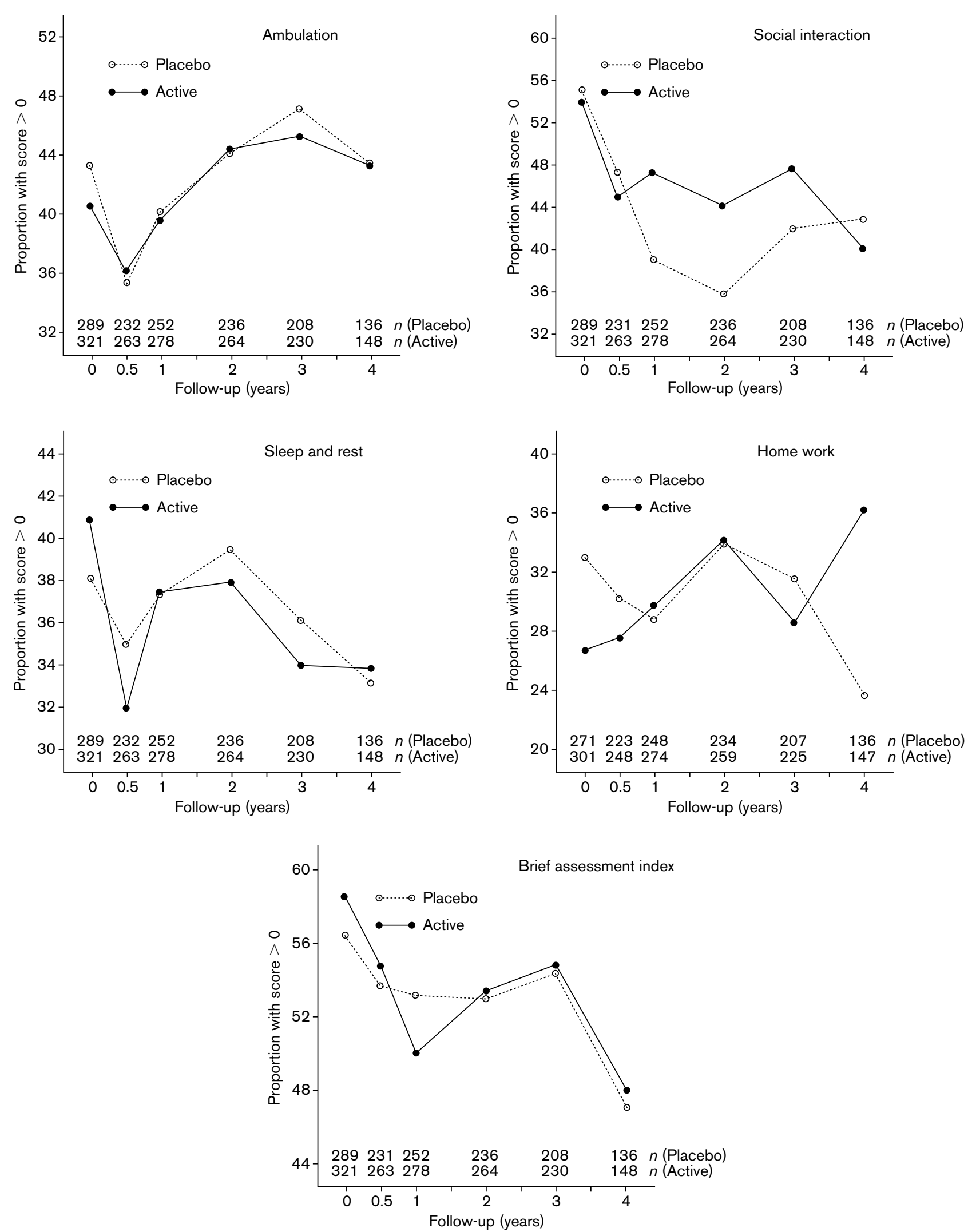

Proportions of patients scoring more than 0 in the randomised treatment analyses for Sickness Impact Profile for (a) ambulation, (b) social interaction, (c) sleep and rest and (d) home work, and for (e) the Brief Assessment Index. 
of follow-up. In the multilevel model for the ITT population, and taking account of baseline scores, significant time trends were observed for ambulation and home work, with the proportion reporting problems increasing over the years of follow-up, but there were no differences between active and placebo treatments in the rate of increased reporting of problems (Table 3). The social interaction scale showed no time effects, but significant treatment differences in favour of placebo $(P=0.03)$. The odds ratio for an adverse effect of active treatment on social interaction was 1.32 [95\% confidence interval (CI) 1.02 to 1.69]. The ORT analyses showed similar results and, in addition, a significant time-by-treatment interaction for home work, with greater improvements for patients receiving placebo at the last period of follow-up.

\section{Trail-making performance (Trail-making tests $A$ and $B$ )}

When changes in time to complete Trail-making tests $\mathrm{A}$ and $\mathrm{B}$ were compared at the 6-month time-point, patients taking placebo had greater improvements than did those receiving active treatment (Table 4). A significant difference $(P=0.006)$ was observed for Trail-making A, whereas for Trail-making $B$ the differences were not significant $(P=0.15)$. There were no differences at the 2-year time-points for either Trailmaking A or Trail-making B. The ORT analyses were essentially identical. Figure 3 shows the results over the 4 years of the trial. In the multilevel analysis for Trail-making A using the ITT population, taking account of all data in the 4-year follow-up period, significant treatment effects in favour of placebo

Table 3 Age-adjusted estimates of treatment and time effects from multilevel model for the intention-to-treat population

\begin{tabular}{lcc}
\hline & Treatment effect & Time effect $\dagger$ \\
\hline Ambulation & $0.99(0.74$ to 1.33$)$ & $1.27(1.18$ to 1.37$)$ \\
Social interaction & $1.32(1.02$ to 1.69$)$ & $1.04(0.97$ to 1.12$)$ \\
Home work & $1.13(0.84$ to 1.53$)$ & $1.10(1.02$ to 1.19$)$ \\
Sleep and rest & $0.84(0.65$ to 1.08$)$ & $1.06(0.98$ to 1.14$)$ \\
Brief Assessment Index & $0.95(0.74$ to 1.19$)$ & $0.99(0.93$ to 1.07$)$ \\
\hline
\end{tabular}

Values are odds ratio and $95 \%$ confidence intervals. $†$ Per year of follow-up.
$(P=0.01)$ were shown, together with a significant timeby-treatment interaction $(P=0.03)$, mainly as a result of larger differences being observed in the earlier period of follow-up (Table 5). The results for Trailmaking $\mathrm{B}$ for the ITT population showed smaller treatment effects $(P=0.07)$ and significant time-bytreatment interactions $(P=0.03)$. The ORT analyses for Trail-making A showed significant treatment effects in favour of placebo $(P=0.05)$ across the 4 years of the trial, but no time-by-treatment interaction $(P=0.10)$. For Trail-making $\mathrm{B}$, the ORT analyses showed no significant treatment effects $(P=0.56)$, or time-bytreatment effects $(P=0.14)$, although completion times tended to be slower in those receiving active treatment in the earlier part of the follow-up period.

In the Trail-making analyses, we excluded a small proportion of patients (around 3\% at each time point) who had either incorrectly completed or been unable to complete the task. We re-ran all analyses, including these patients and assigning their scores to the slowest score recorded for patients who had completed the task correctly. The results were virtually unchanged from those reported above.

In order to investigate whether the 6-month differences were related to the greater decreases in blood pressure observed in those receiving active treatment, we examined the correlations between changes in systolic pressure and changes in completion times. The correlation coefficients were extremely low: $r=0.08 \quad(P=0.24)$ and $r=0 \quad(P=1.0)$ for Trail-making $\mathrm{A}$ and systolic blood pressure for the placebo and active-treatment groups, respectively, and $r=0.06(P=0.41)$ and $r=$ $0.04(P=0.53)$ for Trial-making B. Adjusting for blood pressure over follow-up in the multilevel models also did not change the results observed for either the Trail-making tests or the quality of life scores.

\section{Discussion}

The results from the quality of life assessment in the Syst-Eur trial suggested that active treatment had some

Table 4 Changes in Trail-making tests $\uparrow$ from baseline to 6 months and to 2 years (intention-to-treat analysis)

\begin{tabular}{|c|c|c|c|c|c|c|}
\hline & \multicolumn{6}{|c|}{ Differences from baselinet at: } \\
\hline & \multicolumn{3}{|c|}{6 months } & \multicolumn{3}{|c|}{2 years } \\
\hline & Placebo & Active treatment & $P$ & Placebo & Active treatment & $P$ \\
\hline Trail-making test $\mathrm{A}$ & $(n=227)$ & $(n=261)$ & & $(n=230)$ & $(n=259)$ & \\
\hline$\%$ change & -16.3 & -8.4 & 0.006 & -15.8 & -13.6 & 0.46 \\
\hline $95 \% \mathrm{Cl}$ & -20.3 to -2.0 & -12.1 to -4.6 & & -20.2 to -11.3 & -17.3 to $-9.7 \%)$ & \\
\hline Trail-making test $\mathrm{B}$ & $(n=219)$ & $(n=249)$ & & $(n=223)$ & $(n=251)$ & \\
\hline$\%$ change & -10.2 & -5.9 & 0.15 & -10.5 & -10.9 & 0.89 \\
\hline $95 \% \mathrm{Cl}$ & -14.4 to -5.7 & -9.8 to -1.8 & & -15.0 to -5.8 & -15.4 to -6.2 & \\
\hline
\end{tabular}

$\uparrow$ The reported figures are geometric means expressed as a percentage (antilog of a difference between two log-transformed variables is a ratio). $\$$ Negative score denotes improvement in time to complete task. $\mathrm{Cl}$, confidence interval. 
adverse impacts on quality of life compared with placebo. Although the analyses of changes from baseline to two time-points (6 months and 2 years) found no significant differences for any of the SIP dimensions, an analysis that included data from all time-points over

Fig. 3
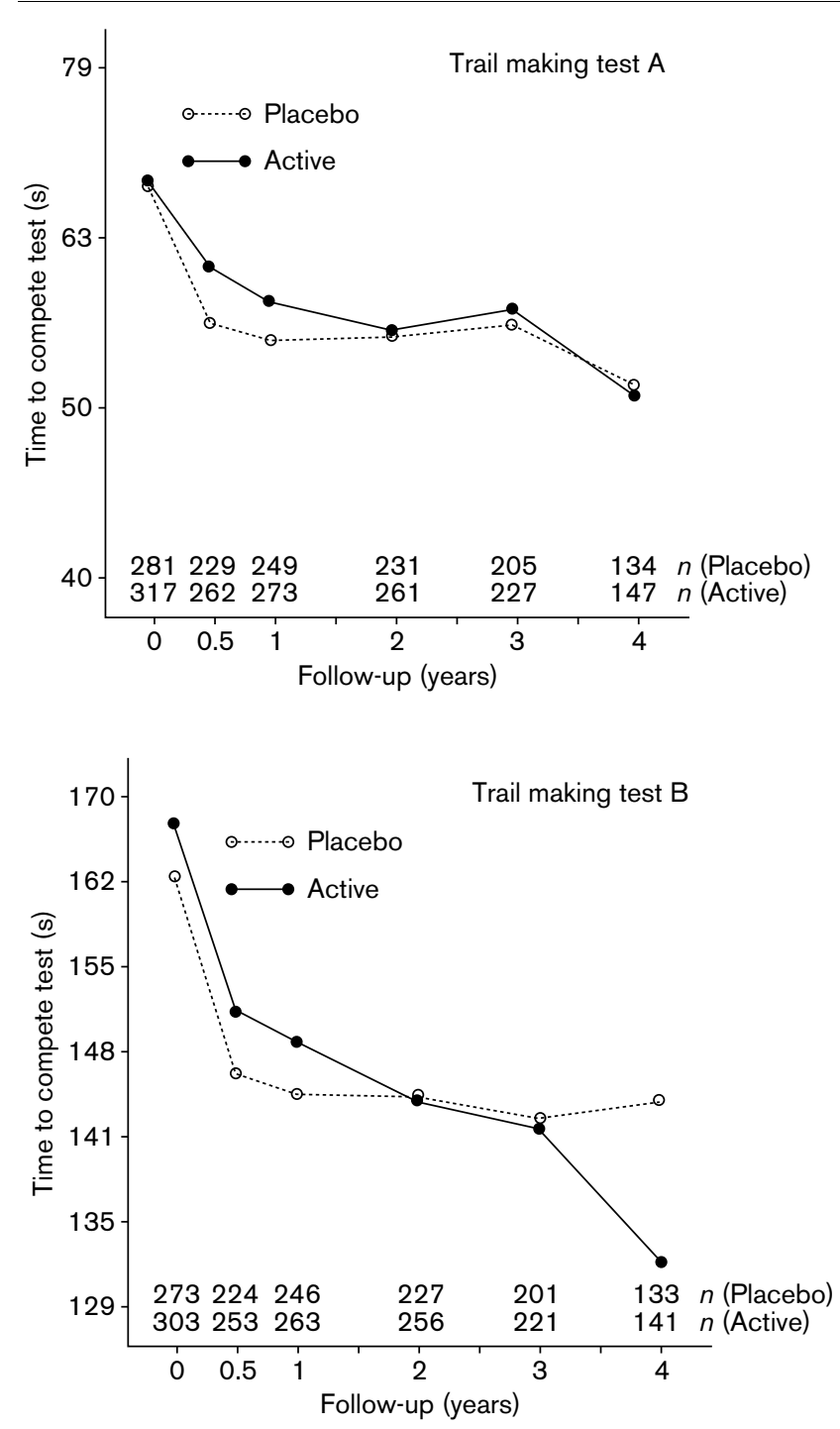

Times to complete Trail-making tests A and B. (Incorrect and unfinished tests were excluded) the 4 years of follow-up and also adjusted for age and baseline values showed significant between-group differences, with greater proportions of actively treated patients reporting problems on the social interaction dimension. These problems may reflect treatment side effects observed in the trial, of which the most important were flushing, oedema and headache with nitrendipine, and cough with enalapril [17]. No overall treatment differences were observed for the SIP dimensions, which measure aspects of physical functioning (ambulation and home work), or with problems with sleep, although there was some suggestion of an adverse treatment effect in the 4th year of follow-up for the dimension 'home work'. The SHEP trial used different measures of quality of life than Syst-Eur, but included some questions on similar areas. In that trial, Activity of Daily Living measures showed a small deterioration in both groups, but there were no differences in overall scores between the two groups [3]. For some individual activities (e.g. dressing, eating, using the toilet, going upstairs and some leisure activities such as taking walks), there were small benefits in favour of the active treatment group. These differences were not explained by the reduced cardiovascular events in that group.

Reassuringly, there were no adverse effects from active treatment on measures of depression in the Syst-Eur trial. In the SHEP trial there was some evidence for a worsening of mood scores among those receiving placebo which, although statistically significant, was of a very small magnitude [3].

The results from the Syst-Eur trial showed a slower rate of learning of the Trail-making tests in actively treated patients. The largest difference was in the first 6 months of follow-up and was not related to the magnitude of the blood pressure reduction. It might be expected that patients receiving placebo, with a smaller reduction in blood pressure, would show a reduced learning effect compared with actively treated patients who had larger decreases in blood pressure, especially in the first 6 months of treatment $(20 \mathrm{mmHg}$ in the active treatment group and $10 \mathrm{mmHg}$ in the placebo group). Previous studies have suggested an inverse association between blood pressure and cognitive performance, especially for memory and attention [18].

Table 5 Regression coefficients for the Trail-making tests from the multilevel model for the intention-totreat population

\begin{tabular}{lccc}
\hline & Treatment effect $\dagger$ & Time effect & Interaction \\
\hline Trail-making A & $0.0305(0.0072$ to 0.0538$)$ & $0.0036(-0.0023$ to 0.0095$)$ & $-0.0092(-0.0174$ to -0.0010$)$ \\
Trail-making B & $0.0216(-0.0021$ to 0.0453$)$ & $0.0065(-0.0006$ to 0.0136$)$ & $-0.0111(-0.0211$ to -0.0011$)$ \\
\hline & $\dagger$ The treatment effects at $z$ years are the ratio of active/placebo given by the equations: & \\
$10^{(0.0305-z[0.0092])}$ for Trail-making $A$, and $10^{(0.0216-z[0.0111])}$ for Trail-making $B$.
\end{tabular}


However, the evidence is strongest for associations between blood pressures measured in mid life and subsequent cognitive decline $[19,20]$.

One of the difficulties in disentangling the relationships between blood pressure and cognitive functioning is that antihypertensive drugs might interfere with certain aspects of cognitive functioning and hence negate any benefits of blood pressure decreasing. An adverse effect on performance in Trail-making tests has clearly been demonstrated for older classes of drugs, such as methyldopa [21], with effect sizes of 0.3 for the difference with captopril at 6 months, where effect sizes of 0.3 are considered to represent a small but noticeable treatment effect, and those of 0.2 or less are considered to be of minimal impact. In comparison, in the present study, the between-group effect sizes at 6 months were 0.25 (95\% CI 0.07 to 0.43 ) for Trail-making A and 0.13 (95\% CI -0.05 to 0.31 ) for Trail-making B. The evidence for other drugs is mixed. In middle-aged hypertensive patients, negligible between-drug differences in Trail-making tests, or other measures of memory or alertness, have been found in trials that have compared a range of classes of antihypertensive agents, including calcium channel blockers (such as nifedipine) and angiotensin-converting enzyme inhibitors (including enalapril) [22]. In older hypertensive patients, the evidence is less reassuring. A small crossover trial of atenolol and nifedipine, using an intensive battery of tests, found significant differences in favour of atenolol in short- and long-term measures of recall [23]. Previous placebo-controlled long-term trials in older people have not found differences between active treatment and placebo in performance on cognitive tests.

In the MRC trial of older people, in a substudy of more than 2000 patients, no differences between placebo or first-line treatment with diuretic or atenolol in measures of memory and attention (including Trail-making A) were observed either in the short term ( 9 months) or over 4.5 years of follow-up [4]. These findings were consistent in both the per-protocol and intention-totreat analyses. The differences between placebo, atenolol and hydrochlorothiazide in the rate of learning of the psychomotor tests were effect sizes of less than 0.05 - that is, one-twentieth of a standard deviation difference. The SHEP trial included a measure of cognitive function in all patients; in addition, in six centres in the trial (with 2000 patients), more detailed and specific tests of cognitive functioning were measured. No differences were observed in the general measure of cognitive function or the more detailed tests. However, patients receiving active treatment reported significantly more troublesome or intolerable problems with memory and concentration compared with placebo (26 compared with $20 \%, P<0.0001$ ) [2].
We did not include either tests of memory or selfreports of memory problems.

The small slowing down of actively treated patients was more noticeable for the simpler task of Trailmaking A. Order effect may be a possible explanation for this, because Trail-making A was consistently given before Trail-making B, so that larger treatment differences might be more likely to show up on the first test, whereas Trial-making B performance would reflect some practice effects from Trail-making A [24]. Trailmaking $\mathrm{B}$ is a more complex task, but may be subject to more 'background noise', because it is affected by other factors such as reading skills [25]. The reduction in the size of the placebo-active treatment differences over follow-up, especially after 2 years of follow-up, was more attributable to an attenuation of the faster performance in Trail-making in the placebo group, perhaps as a result of adverse vascular events.

In the Syst-Eur trial, it is difficult to attribute the observed effects to one particular drug, because patients were allocated randomly to a drug regimen and not to individual drugs. The social interaction results were relatively constant across the trial, although the proportions of individuals taking first-line drugs varied. However, it is likely that the Trail-making results, which were most pronounced at 6 months, may be related to nitrendipine treatment, because, at the 6month period, $57 \%$ of individuals were taking this as the first-line drug alone, and a further $13 \%$ were taking nitrendipine in combination with one or both of the second- and third-line drugs; $10 \%$ were taking enalapril only, and two patients were taking hydrochlorothiazide only.

Our results on social interaction and Trail-making performance also need to be considered in the light of the positive benefit from active treatment in stroke $(42 \%$ reduction), all cardiovascular endpoints (31\% reduction) [7] and a lower incidence of dementia (7.7 per 1000 person years with placebo compared to 3.8 per 1000 person years with active treatment, $P=0.05$ ) [26]. The size of adverse effects reported in this paper were small. There was an increased odds ratio of 1.32 for reporting problems on the social interaction scale, but the confidence intervals were wide (1.02 to 1.69$)$ and the proportion who reported no problems was high even after 4 years of follow-up (46\% receiving active treatment and $53 \%$ receiving placebo). For the Trailmaking tests, the overall effect of active treatment was a $7 \%$ increase in time to complete Trail-making $\mathrm{A}$ and a $5 \%$ increase for Trail-making B. This attenuated with follow-up, such that, by the 1-year point, the treatment effect was 5\% for Trail-making A and 2\% for Trailmaking B. However, it is possible that adverse effects may have been underestimated, as participants in the 
quality of life study were more likely to be newly treated for hypertension and also had fewer cardiovascular complications than non-participants. Whether better effects on quality of life in older individuals with hypertension would be observed with other classes of antihypertensive drugs is being investigated in current trials $[27,28]$.

\section{Acknowledgements}

We would like to thank the interviewers at the study centres, and Jill Grove at the Hammersmith Hospital for quality control and data monitoring.

\section{References}

1 Staessen JA, Gasowski J, Wang JG, Thijs L, Den Hond E, Boissel JP, et al. Risks of untreated and treated isolated systolic hypertension in the elderly: meta-analysis of outcome trials. Lancet 2000; 355:865-872.

2 SHEP Cooperative Research Group. Prevention of stroke by antihypertensive drug treatment in older persons with isolated systolic hypertension: final results of the Systolic Hypertension in the Elderly Program (SHEP). JAMA 1991; 265:3255-3264.

3 Applegate WB, Pressel S, Wittes J, Luhr J, Shekelle RB, Camel GH, et al. Impact of the treatment of isolated systolic hypertension on behavioral variables. Results from the Systolic Hypertension in the Elderly Program. Arch Intern Med 1994; 154:2154-2160.

4 Prince MJ, Bird AS, Blizard RA, Mann AH. Is the cognitive function of older patients affected by antihypertensive treatment? Results for 54 months of the MRC's trial of hypertension in older adults. BMJ 1996; 312:801-805.

5 Fletcher AE, Bulpitt CJ, Tuomilehto J, Brown J, Bossini A, Kawecka-Jaszcz $\mathrm{K}$, et al., on behalf of the Syst-Eur Trial Investigators. Quality of life in elderly patients with isolated systolic hypertension: baseline data from the Syst-Eur Trial. J Hypertens 1998; 16:1117-1124.

6 Amery A, Birkenhager W, Bulpitt CJ, Clement D, De Leeuw P, Dollery $\mathrm{CT}$, et al. Syst-Eur. A multicentre trial on the treatment of isolated systolic hypertension in the elderly: objectives, protocol and organization. Aging Clin Exp Res 1991; 3:287-302.

7 Staessen JA, Fagard R, Thijs L, Celis H, Arabidze GC, Birkenhager WH, et al., for the Systolic Hypertension in Europe (Syst-Eur) Trial Investigators. Morbidity and mortality in the European trial of isolated systolic hypertension in the elderly. Lancet 1997; 350:757-764.

8 Fletcher A, Bulpitt C, Amery A, Battersby C, Cox J, O'Brien E, et al. The assessment of quality of life in the SYST-EUR trial. High Blood Press 1993; 2:45-50.

9 Reitan RM. Validity of the trail making test as an indicator of organic brain damage. Percept Mot Skills 1958; 8:271-276.

10 Breteler MM, van Amerongen NM, van Swieten JC, Claus JJ, Grobbee $\mathrm{DE}$, van Gijn J, et al. Cognitive correlates of ventricular enlargement and cerebral white matter lesions on magnetic resonance imaging. The Rotterdam Study. Stroke 1994; 25: 1109-1115.

11 van Swieten JC, Geyskes GG, Derix MMA. Hypertension in the elderly is associated with white matter lesions and cognitive decline. Ann Neurol $1991 ; 30: 825-830$.

12 Bergner M, Bobbit RA, Carter WB, Gilson, BS. The Sickness Impact Profile: development and final revision of a health status measurement. Med Care 1981; 19:787-805.

13 Adshead F, Codey DD, Pitt B. BASDEC: a novel screening instrument for depression in elderly medical in-patients. BMJ 1992; 305:397.

14 Patrick DL, Peach H. Disablement in the community. Oxford: Oxford University Press; 1978.

15 Hedges LV, Olkin I. Estimation of a single effect size. Parametric and non-parametric methods. In: Hedges LV, Olkin I (editors): Statistical methods for meta-analysis, ch 5. San Diego, California: Academic Press, Inc.; 1985.

16 Diggle PJ, Liang KY, Zeger SL. The analysis of longitudinal data. New York: Oxford University Press; 1994.

17 Bulpitt CJ, Beckett NS, Fletcher AE, Thijs L, Staessen JA, Dumitrascu DL, et al., for The Syst-Eur investigators. Withdrawal from treatment in the Syst-Eur Trial. J Hypertens 2002; 20:339-346.

18 Starr JM, Whalley LJ. Senile hypertension and cognitive impairment: an overview. J Hypertens Suppl 1992; 10: S31-S42.

19 Elias MF, Wolf PA, D'Agostino RB, Cobb J, White LR. Untreated blood pressure level is inversely related to cognitive functioning: the Framingham Study. Am J Epidemiol 1993; 138:353-364.

20 Launer LJ, Masaki K, Petrovitch H, Foley D, Havlik RJ. The association between midlife blood pressure levels and late-life cognitive function. The Honolulu-Asia Aging Study. JAMA 1995; 274:1846-1851.

21 Croog SH, Levine S, Testa MA, Brown B, Bulpitt CJ, Jenkins CD, et al The effects of antihypertensive therapy on the quality of life. $N$ Engl $J$ Med 1986; 314:1657-1664.

22 Fletcher A. Quality of life in the management of hypertension. In: Proceedings of the WHO/ISH International Expert meeting on Hypertension. Clin Exp Hypertens 1999; 21:961-972.

23 Skinner MH, Futterman A, Morrissette D, Thomposon L, Hoffman BB, Blasche TF. Atenolol compared with nifedipine: effect on cognitive function and mood in elderly hypertensive patients. Ann Int Med 1992; 116:615-623.

24 Taylor R. Order effects within the Trail Making and Stroop tests in patients with neurologic disorders. J Clin Exp Neuropsychol 1998; 20:750-754.

25 Crowe SF. The differential contribution of mental tracking, cognitive flexibility, visual search and motor speed to performance on parts $A$ and B of the Trail Making Test. J Clin Psychol 1998; 54: 585-591.

26 Forette F, Seux ML, Staessen JA, Thijs L, Birkenhager WH, Babarskiene $\mathrm{MR}$, et al. Prevention of dementia in randomised double-blind placebocontrolled Systolic Hypertension in Europe (Syst-Eur) trial. Lancet 1998; 352:1347-1351.

27 Davis BR, Cutler JA, Gordon DJ, Furberg CD, Wright JT Jr, Cushman $W C$, et al. Rationale and design for the Antihypertensive and Lipid Lowering Treatment to Prevent Heart Attack Trial (ALLHAT). ALLHAT Research Group. Am J Hypertens 1996; 9:342-360.

28 Bulpitt C, Fletcher A, Beckett N, Coope J, Blas Gil-Extremara, Forette F, et al. Hypertension in the Very Elderly Trial (HYVET). Protocol for the main trial. Drugs Ageing 2001; 18:151-164.

\section{Appendix}

Investigators

The following participated in the SYST-EUR Quality of Life Project:

\section{Belgium \\ R. Fagard (Leuven).}

\section{Croatia}

Z. Rumboldt (Split).

\section{Finland}

R. Antikainen (Oulu), T.T. Hakamäki (Turku), K. Halonen (Kuusankoski), M. Jääskivi (Vantaa), P. Kivinen (Kuopio), P. Kuusisto (Ilomantsi), E. Lehtomäki (Tampere), A. Lehtonen, R. Ruotsalainen (Liperi), R. Tilvis, H. Vanhanen (Helsinki), O. Vänska (Joensuu).

\section{Ireland}

L. Bradley, J. Duggan, E. O’Brien (Dublin).

\section{Italy}

A. Bossini (Rome), G. Maiorano (Bari), P. Palatini (Padova), C. Pasotti (Voghera), A. Pirrelli (Bari), R. Rappelli (Ancona), L. Terzoli (Milan), A. Vaccarella (Casatenova).

\section{Lithuania}

D Rastenyte (Kaunda). 
Poland

K. Kawecka-Jaszcz, J. Kocemba (Krakow).

Rumania

S. Babeanu (Bucharest), D. Dumitrascu (Cluj).

\section{Russian Federation}

A. Ivleva, V. Moissseyev (Moscow).

Slovakia

Z. Gerova (Bratislava).

Spain

B.G. Extremera (Granada).

United Kingdom

C. Bulpitt (London), C. Davidson (Brighton), P.R. Wilkinson (Ashford).

\section{Committees and co-ordination}

\section{Data monitoring committee}

C.J. Bulpitt, A.E. Fletcher, J. Staessen, L. Thijs.

\section{Endpoint committee}

P. De Leeuw, R. Fagard, G. Leonetti, J. Petrie.

\section{Ethics committee}

W. Birkenhager, C.T. Dollery, R. Fagard.

\section{Steering committee}

P. De Cort, R. Fagard, F. Forette, K. Kawecka-Jaszcz, G. Leonetti, C. Nachev, E. O'Brien, J. Rodico, J. Rosenfeld, J. Tuomilehto, J. Webster, Y. Yodfat.

\section{Trial coordinators}

R. Fagard, J. Staessen.

\section{Coordinators of the side-project on Ambulatory Blood}

Pressure Monitoring

D. Clement, E. O’Brien, G. Mancia, G. Parati, J. Staessen, L. Thijs.

Coordinators of the side-project on Vascular Dementia

F. Forette, T. Strasser.

\section{Coordinators of the side project on Quality of Life}

C.J. Bulpitt, A.E. Fletcher.

\section{Coordination of the General Practitioners}

H. Celis.

\section{Coordinating office}

N. Ausseloos, H. Celis, E. Den Hond, L. De Pauw, P. Drent, R. Fagard, H. Fan, J. Staessen, L. Thijs, Y. Toremans, S. Van Hulle, J. Wang, R. Wolfs.

\section{Contributors}

J. Staessen is the principal coordinator of the Syst-Eur Trial. A. Fletcher and C. Bulpitt are the principal coordinators of the quality of life side study and responsible for its design and implementation. A. Fletcher specified the analyses for the paper and wrote the manuscript, and all authors commented on drafts. L. Thijs undertook all statistical analyses. R. Antikainen, A. Bossini, J. Browne, J. Duggan, K. KaweckaJaszcz, P. Kivinene, L. Terzoli and J. Tumilheto were clinical investigators and local coordinators of the quality of life study. 